\title{
COMPRESSIBILIDADE, RESISTÊNCIA A PENETRAÇÃO E INTERVALO HÍDRICO ÓTIMO DE UM ARGISSOLO AMARELO CULTIVADO COM CANA-DE-AÇÚCAR NOS TABULEIROS COSTEIROS DE ALAGOAS ${ }^{(1)}$
}

\author{
Edson Patto Pacheco ${ }^{(2)}$ \& José Ramon Barros Cantalice ${ }^{(3)}$
}

\begin{abstract}
RESUMO
O tráfego intenso de máquinas agrícolas para colheita e tratos culturais em plantações de cana-de-açúcar pode causar a compactação do solo e comprometer a produtividade e longevidade da lavoura. Uma das formas de avaliar e monitorar a degradação devido à compactação causada pelo trânsito das máquinas é por meio da análise da compressibilidade e comportamento hídrico do solo. Este trabalho teve como objetivo avaliar o efeito do trânsito de máquinas para o cultivo da cana-de-açúcar sobre a pressão de pré-compactação $\left(\sigma_{\mathrm{p}}\right)$, resistência à penetração em laboratório (RPL) e intervalo hídrico ótimo (IHO) de um Argissolo Amarelo distrocoeso dos Tabuleiros Costeiros do Estado de Alagoas. O trabalho foi desenvolvido na Fazenda Progresso, de propriedade da Usina Coruripe (AL), onde foram selecionadas cinco áreas cultivadas com cana-de-açúcar, representando diferentes tempos de uso e dois tipos de cultivo: 4 anos com cultivo de inverno (4 anos I); 14 anos com cultivo de inverno (14 anos I); 14 anos com cultivo de verão (14 anos V); 30 anos com cultivo de inverno (30 anos I); 30 anos com cultivo de verão (30 anos V) e uma área de mata (mata), tipo floresta subperenifólia, como testemunha. Avaliaram-se a $\sigma_{\mathrm{p}}$, a RPL e o IHO, nas profundidades de 0 a 0,20, 0,20 a 0,40 e 0,40 a 0,60 m, correspondendo aos horizontes A (mata) ou Ap (áreas cultivadas), AB e Bt. O cultivo com cana-de-açúcar aumentou a $\sigma_{\mathrm{p}}$ e a RPL dos horizontes Ap, AB e Bt do Argissolo Amarelo estudado; no entanto, o horizonte Ap do solo das áreas cultivadas não mostrou RPL superior a valores considerados críticos ao desenvolvimento de raízes, apresentando IHO maior do que o horizonte superficial (A) do solo sob mata nativa. As operações mecanizadas utilizadas no cultivo da cana-de-açúcar aumentaram a RPL para níveis críticos ao desenvolvimento de raízes, mesmo para umidades próximas à da capacidade de
\end{abstract}

\footnotetext{
(1) Parte da Tese de Doutorado do primeiro autor. Programa de Pós-graduação em Ciência do Solo da Universidade Federal Rural de Pernambuco - UFRPE. Recebido para publicação em março de 2010 e aprovado em dezembro de 2010.

${ }^{(2)}$ Pesquisador da Embrapa Tabuleiros Costeiros. Avenida Beira Mar 3250, Jardins, Caixa Postal 44, CEP $49025-040$ Aracaju (SE). E-mail: patto@cpatc.embrapa.br

(3) Professor do Programa de Pós-Graduação em Ciência do Solo, Universidade Federal Rural de Pernambuco - UFRPE. Departamento de Agronomia. R. Dom Manoel de Medeiros s/n, Dois Irmãos, CEP 52171-900 Recife (PE). E-mail: cantalic@terra.com.br
} 
campo, o que resulta na redução do IHO dos horizontes AB e Bt do solo das áreas cultivadas. A pressão de pré-compactação deve ser usada como capacidade de suporte de carga no planejamento de operações mecanizadas em lavouras de canade-açúcar, a fim de evitar a degradação física de horizontes subsuperficiais do Argissolo Amarelo distrocoeso.

Termos de indexação: compactação do solo, pressão de pré-compactação, comportamento hídrico.

\title{
SUMMARY: COMPRESSIBILITY, PENETRATION RESISTANCE AND LEAST LIMITING WATER RANGE OF A YELLOW ULTISOL UNDER SUGARCANE IN THE COASTAL TABLELANDS OF ALAGOAS STATE
}

\begin{abstract}
The intensive traffic of agricultural machinery of cultivation and harvesting operations of sugarcane can promote soil compaction and affect crop yield and longevity. One of the ways to evaluate soil degradation due to compaction is by analyses of soil compressibility and least limiting water range. The objective of this study was to evaluate the effect of sugarcane cultivation on pre-compaction pressure $(\sigma p)$, laboratory-determined soil penetration resistance (LPS) and on the least limiting water range (LLWR) of a cohesive Yellow Ultisol of the coastal tablelands of Alagoas. The study was conducted on the Fazenda Progresso, of the Usina Coruripe, where five sugarcane areas were selected, representing different use periods and crop systems: four years under winter cropping (4 year $W$ ), 14 years under winter cropping (14 year $W$ ), 14 years under summer cropping (14 year $S)$, thirty years under winter cropping (30 year $W)$, and 30 years under summer cropping (30 year $S$ ). A native subperennial forest fragment (Forest) was also included in this study as a reference area. To determine the effect of sugarcane cultivation on soil compaction, $\sigma p, L P S$ and LLWR were determined in soil samples from the layers 0 $0,20 \mathrm{~m}, 0,20-0,40 \mathrm{~m}$ and 0,40-0,60 $\mathrm{m}$, corresponding to the horizons $A$ (Forest) or Ap (agricultural areas), $A B$ and Bt. Sugarcane cultivation increased the $\sigma_{p}$ and LPS of the Ap, AB and Bt horizons of the Yellow Ultisol, however, in the Ap horizon of the soil of the agricultural areas the LPS did not reach the value considered critical for root development, and the LLWR was higher than in the surface horizon of native forest. The mechanized operations for sugarcane cultivation increased LPS to critical levels for root development, even at moisture contents near field capacity, which decreased LLWR of $A B$ and Bt horizons in the agricultural areas. Precompaction pressure can be used as an indicator of load support capacity in the strategic planning of machinery operations in sugarcane fields, in order to avoid further soil compaction in the subsurface horizons of cohesive Yellow Ultisol.
\end{abstract}

Index terms: Soil compaction, pre-compaction pressure, soil water behavior.

\section{INTRODUÇÃO}

No Nordeste, a cana-de-açúcar ocupa grande área do ecossistema dos Tabuleiros Costeiros, onde a topografia, a profundidade e a textura dos solos são favoráveis ao cultivo dessa importante cultura. Entretanto, devido à grande quantidade de operações motomecanizadas realizadas em curto espaço de tempo, os solos da áreas cultivadas com cana são submetidos a pressões excessivas em condições de teor de umidade que favorecem o processo de degradação física, resultando em compactações adicionais.

A pressão exercida na superfície do solo pelo tráfego de máquinas, normalmente, aumenta a densidade do solo e diminui a porosidade total, sobretudo a macroporosidade (Tsegaye \& Hill, 1998), sendo mais grave quando as operações de preparo do solo e tráfego de máquinas são realizadas aplicando-se pressões superiores à capacidade de suporte de carga, para um dado teor de umidade do solo (Dias Junior \& Pierce, 1996; Dias Junior, 2000).

A pressão de pré-compactação $\left(\sigma_{\mathrm{p}}\right)$, que é determinada pela curva de compressão obtida com ensaio de adensamento uniaxial (ABNT, 1990; Dias Junior, 2000) é uma das formas utilizadas para estimar a compactação do solo. Essa variável determina a maior pressão que o solo já sofreu no passado e representa a capacidade de suporte de carga, ou seja, a pressão máxima que o solo suporta antes que ocorra compactação adicional (Dias Junior \& Pierce, 1996). 
A $\sigma_{\mathrm{p}}$ está relacionada com a resistência do solo à penetração das raízes, e valores elevados de pressão de pré-compactação apresentam maior probabilidade de reduzir o crescimento das raízes (Römkens \& Miller, 1971). Considerando que a $\sigma_{\mathrm{p}}$ e a resistência do solo à penetração variam em função do teor de umidade e que existe relação significativa, positiva e linear entre as duas variáveis, pode-se afirmar que uma pode ser estimada a partir da outra, por meio de modelos matemáticos (Lima \& Silva, 2006).

O Intervalo Hídrico Ótimo (IHO) incorpora em um único dado a amplitude do teor de umidade do solo em que são mínimas as limitações ao desenvolvimento de plantas associadas à disponibilidade de água, aeração e resistência do solo à penetração. Por isso o IHO integra as propriedades físicas do solo que diretamente influenciam o desenvolvimento das culturas. Essas inter-relações dependem da condição estrutural do solo e, portanto, do grau de degradação da estrutura a que ele está submetido. Portanto, o IHO pode ser utilizado como indicador da qualidade e condição estrutural do solo (Tormena et al., 1998).

O objetivo deste trabalho foi avaliar o efeito do cultivo com cana-de-açúcar sobre a pressão de pré-compactação, a resistência à penetração e alterações do intervalo hídrico ótimo (IHO) de um Argissolo Amarelo distrocoeso dos Tabuleiros Costeiros do Estado de Alagoas.

\section{MATERIAL E MÉTODOS}

O trabalho foi desenvolvido em área localizada entre os paralelos $10^{\circ} 01^{\prime} 59$ " e $10^{\circ} 02$ ' $58^{\prime \prime} \mathrm{S}$ e os meridianos $36^{\circ} 10$ ' 22 " e $36^{\circ} 12$ ' 35 " W, da Fazenda Progresso, de propriedade da Usina Coruripe, no município de Coruripe-AL. O clima do local é tropical chuvoso com verão seco, segundo Köppen. A pluviosidade média anual é de aproximadamente $1.400 \mathrm{~mm}$, e a temperatura média, de $24,4^{\circ} \mathrm{C}$. O solo avaliado foi classificado como Argissolo Amarelo distrocoeso, relevo plano, textura média (leve)/argilosa (Embrapa, 2006), formado do sedimento Grupo Barreiras, característico da unidade geomorfológica Tabuleiros Costeiros (Jacomini et al., 1975).
Foram selecionadas cinco áreas cultivadas com cana-de-açúcar, representando diferentes tempos de uso e dois tipos de cultivo: 4 anos com cultivo de inverno (4 anos I); 14 anos com cultivo de inverno (14 anos I); 14 anos com cultivo de verão (14 anos V); 30 anos com cultivo de inverno (30 anos I); 30 anos com cultivo de verão (30 anos V); e uma área de mata (mata), tipo floresta subperenifólia, que foi considerada testemunha, totalizando seis tratamentos. No sistema de cultivo de inverno não há preparo do solo com grade, ocorre adubação verde com Crotalaria espectabilis e a cana é plantada no final do período chuvoso (inverno). No cultivo de verão ocorre a gradagem e aplicação de composto orgânico no sulco de plantio, que é realizada no período seco (verão). Em toda a área cultivada havia sido realizada a subsolagem, para implantação dos canaviais que estavam no quarto corte.

Para realização das análises físicas e da matéria orgânica, foram retiradas amostras de solo em quatro repetições para cada área, nas profundidades de $0 \mathrm{a}$ 0,20, 0,20 a 0,40 e 0,40 a 0,60 m, correspondendo aos horizontes A (mata) ou Ap (áreas cultivadas), $\mathrm{AB}$ e $\mathrm{Bt}$, respectivamente.

A composição granulométrica do solo foi determinada pelo método do densímetro de Boyoucos (Embrapa, 1997), cujas médias dos teores de areia, silte e argila dos seis tratamentos nas três profundidades estudadas são apresentadas no quadro 1.

Para determinação da curva característica de retenção de água, da pressão de pré-compactação $\left(\sigma_{\mathrm{p}}\right)$ e da resistência do solo à penetração em laboratório (RPL), foram utilizadas amostras indeformadas, extraídas do solo em anéis volumétricos de PVC com $5,2 \mathrm{~cm}$ de diâmetro e $2,0 \mathrm{~cm}$ de altura, por meio de trado de Uhland, conforme descrito por Pacheco (2010). Quanto à elaboração da curva de retenção de água, as amostras indeformadas foram saturadas por $24 \mathrm{~h}$ para posterior estabilização do teor de umidade em oito sucções de potenciais matriciais $(-1,-4,-6,-10,-33$, $100,-500$ e $-1.500 \mathrm{kPa}$ ), utilizando mesa de tensão e câmara de Richards (Embrapa, 1997). Estabilizado o teor de umidade, as amostras foram submetidas ao ensaio de RPL, utilizando um penetrógrafo de bancada com cone de $4 \mathrm{~mm}$ de diâmetro, ângulo de $45^{\circ} \mathrm{e}$ velocidade de penetração de $10 \mathrm{~mm} / \mathrm{min}$ (Pacheco, 2010).

Quadro 1. Caracterização granulométrica dos horizontes A (mata) ou Ap (áreas cultivadas), AB e Bt dos seis tratamentos, nas três profundidades estudadas

\begin{tabular}{|c|c|c|c|c|c|c|c|c|c|}
\hline \multirow{2}{*}{ Tratamento } & \multicolumn{3}{|c|}{ Horizonte A ou Ap } & \multicolumn{3}{|c|}{ Horizonte AB } & \multicolumn{3}{|c|}{ Horizonte Bt } \\
\hline & Areia & Silte & Argila & Areia & Silte & $\overline{\text { Argila }}$ & Areia & Sil te & $\overline{\text { Argila }}$ \\
\hline & \multicolumn{9}{|c|}{$\mathrm{g} \mathrm{kg}^{-1}$} \\
\hline Mata & 868 & 57 & 76 & 793 & 56 & 151 & 632 & 78 & 291 \\
\hline 4 anos I & 867 & 46 & 88 & 701 & 65 & 234 & 596 & 102 & 326 \\
\hline $14 \operatorname{anos} I$ & 866 & 49 & 86 & 751 & 66 & 184 & 592 & 102 & 306 \\
\hline 14 anos $\mathrm{V}$ & 873 & 42 & 86 & 768 & 63 & 169 & 606 & 97 & 297 \\
\hline 30 anos I & 885 & 39 & 75 & 747 & 81 & 172 & 608 & 127 & 265 \\
\hline 30 anos $\mathrm{V}$ & 868 & 42 & 91 & 724 & 70 & 207 & 593 & 119 & 288 \\
\hline
\end{tabular}


Após o ensaio de RPL, as amostras foram submetidas ao ensaio de compressão uniaxial, utilizando uma prensa manual, onde foram aplicadas cargas verticais correspondentes a tensões de 12,5, 25, 50, 100, 200, 400, 800 e $1.600 \mathrm{kPa}$, conforme norma de Ensaio de Adensamento Unidimensional-MB 3336 da ABNT (1990). A razão de carga foi igual a 2, e os estádios de carregamento foram de $30 \mathrm{~s}$. Para cada carga aplicada, foi medida a deformação vertical da amostra, por meio de micrômetro com precisão de 0,01 mm. A entrada dos dados de densidade de partícula (método do picnômetro - Embrapa (1997), peso do solo seco, peso do solo úmido, dimensões do anel de PVC e valor da deformação vertical (para cada carga aplicada) foi realizada no programa "Compress" (Reinert et al., 2003), para determinação da pressão de pré-compactação $\left(\sigma_{\mathrm{p}}\right)$, por meio da curva de compressão. O método utilizado para determinação da $\sigma_{\mathrm{p}}$ Pacheco e Silva-03 é descrito na norma MB 3336 da ABNT (1990).

Ao final do ensaio de compressão, as amostras foram secas em estufa a $105{ }^{\circ} \mathrm{C}$ por $24 \mathrm{~h}$, para determinação do teor de umidade gravimétrica (Ug), da densidade do solo (Ds) e dos teores de umidade volumétrica $(\theta)$ relativos aos mesmos potenciais matriciais utilizados na elaboração da curva característica de retenção de água.

Foram realizadas análises de regressão, por meio do programa estatístico SAEG 9.1 (UFV), para obtenção dos parâmetros de ajuste "a" e "b" dos modelos matemáticos de pressão de pré-compactação $\left(\sigma_{p}\right)$ e resistência do solo à penetração em laboratório (RPL), em função do teor de umidade gravimétrica do solo (Ug), conforme os modelos propostos por Dias Junior (2000), descritos a seguir: $\sigma_{\mathrm{p}}=10^{(\mathrm{a}+\mathrm{b} . \mathrm{Ug})}, \mathrm{RPL}=10^{(\mathrm{a}+\mathrm{b} . \mathrm{Ug})}$.

Na determinação do intervalo hídrico ótimo (IHO) foram empregados critérios descritos por Wu et al. (2003):

(a) Se $(\theta p a \geq \theta c c)$ e $(\theta r p \leq \theta p m p)=>$ IHO $=\theta c c-\theta p m p$;

(b) Se $(\theta p a \geq \theta c c)$ e $(\theta r p \geq \theta p m p)=>$ IHO $=\theta c c-\theta r p$;

(c) $\operatorname{Se}(\theta p a \leq \theta c c)$ e $(\theta r p \leq \theta p m p)=>$ IHO $=\theta$ pa $-\theta$ pmp;

(d) Se $(\theta$ pa $\leq \theta c c)$ e $(\theta r p \geq \theta$ pmp $)=>$ IHO $=\theta$ pa $-\theta$ rp.

em que $\theta$ pa: umidade do solo em que a porosidade de aeração é $\leq 0,1 \mathrm{~m}^{3} \mathrm{~m}^{-3}$; $\theta c c$ : umidade do solo na capacidade de campo (água retida a -10 kPa); $\theta$ pmp: umidade do solo no ponto de murcha permanente (água retida na tensão $-1.500 \mathrm{kPa}$ ); $\theta$ rp: umidade do solo quando a resistência à penetração é $\geq 2.000 \mathrm{kPa}$ (obtido por meio da curva de RPL em função da umidade do solo); e IHO: intervalo hídrico ótimo.

\section{RESULTADOS E DISCUSSÃO}

\section{Horizonte A (mata) ou Ap (áreas cultivadas) (0 a $0,20 \mathrm{~m})$}

Nas figuras 1 e 2 são representadas as curvas de regressão da $\sigma_{p}$ e da RPL em função da umidade gravimétrica, para a profundidade de 0 a $0,2 \mathrm{~m}$ do Argissolo, nas seis condições de uso e manejo estudadas.

Por serem dependentes da quantidade de água no solo, tanto a $\sigma_{\mathrm{p}}$ quanto a RPL variaram significativa e inversamente com a umidade do solo (Figuras 1 e 2). Os resultados estão de acordo com Hillel (1980), que afirma que, quanto mais baixos os teores de água, mais resistente fica a matriz do solo, conferindo a este maior resistência às deformações provocadas por pressões externas. A pressão de pré-compactação e a resistência mecânica do solo à penetração tornaramse maiores à medida que o solo ficava mais seco. Isso acontece porque a água atua de duas formas sobre a resistência do solo ao cisalhamento: diminui a coesão

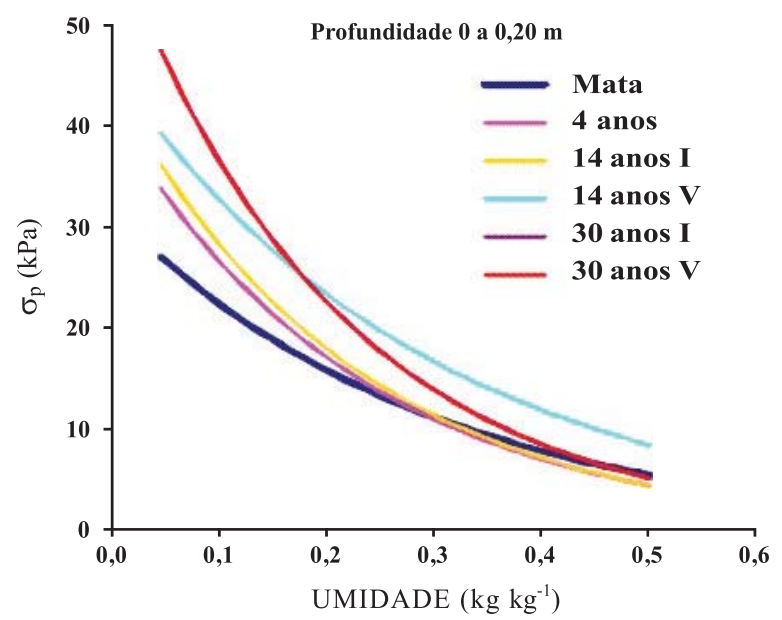

Figura 1. Pressão de pré-compactação $\left(\sigma_{p}\right)$ em função da umidade, na profundidade de 0 a $0,20 \mathrm{~m}$ de um Argissolo Amarelo distrocoeso cultivado com cana-de-açúcar: $\sigma_{p}=10^{(a+b . U g)}$.

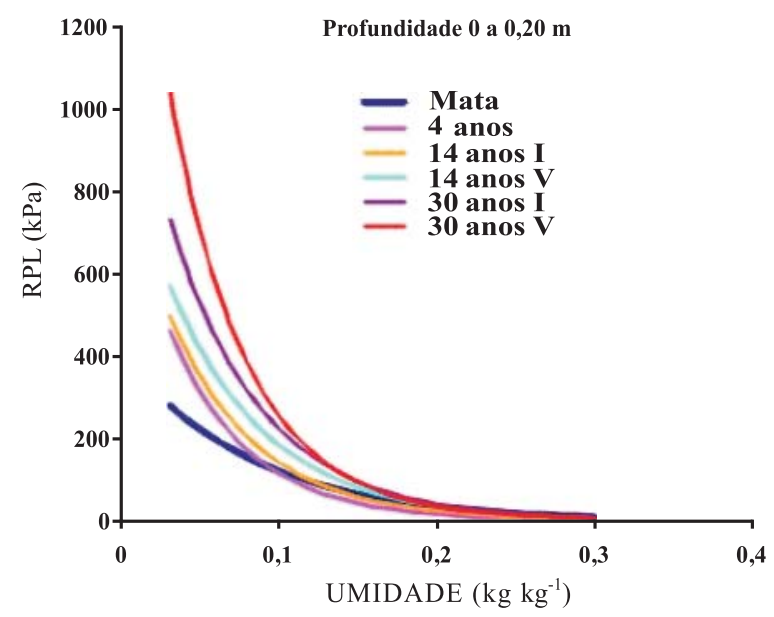

Figura 2. Resistência do solo à penetração em laboratório em função da umidade, na profundidade de 0 a $0,20 \mathrm{~m}$ de um Argissolo Amarelo distrocoeso cultivado com cana-deaçúcar: $\mathrm{RPL}=10^{(\mathrm{a}+\mathrm{b} \cdot \mathrm{Ug})}$. 
entre as partículas sólidas; e forma filmes sobre as partículas sólidas, reduzindo o atrito entre elas. O resultado é um decréscimo exponencial da pressão de pré-compactação e resistência do solo à penetração com o aumento da umidade. Esse comportamento mecânico também foi descrito por Dias Junior (1994), Kondo \& Dias Junior (1999) e Silva et al. (2002).

Na profundidade de 0 a $0,20 \mathrm{~m}$, o Argissolo sob mata apresentou comportamento mecânico distinto em relação às áreas cultivadas, o que pode ser comprovado pelos valores dos coeficientes de ajuste "a" e "b" dos modelos de $\sigma_{\mathrm{p}}$ e RPL, em função da umidade gravimétrica (Quadro 2). Nessa profundidade, o solo da mata apresentou menores valores tanto para o coeficiente angular quanto para o linear, conferindo a esse tratamento uma menor amplitude da $\sigma_{\mathrm{p}}$ e da RPL durante as variações da umidade do solo, em relação às áreas cultivadas. Quando comparadas, as áreas cultivadas apresentaram comportamento semelhante, com exceção do tratamento 14 anos V, que apresentou coeficiente angular similar ao da mata, para o modelo de $\sigma_{\mathrm{p}}$.

Ainda na profundidade de 0 a $0,20 \mathrm{~m}$, observou-se que, em umidades mais elevadas, os solos dos seis tratamentos apresentaram valores de $\sigma_{\mathrm{p}}$ eRPL muito baixos e semelhantes, com variação máxima entre os tratamentos de 7 e $5 \mathrm{kPa}$ para $\sigma_{\mathrm{p}}$ e RPL (Quadro 3), respectivamente. No entanto, observa-se maior diferença entre os tratamentos para umidades mais baixas, havendo a tendência de ocorrerem maiores valores de $\sigma_{\mathrm{p}}$ e RPL nas áreas com maior tempo de cultivo com cana-de-açúcar (Figuras 1 e 2), corroborando os resultados obtidos por Oliveira (2008) e Vasconcelos (2009), quando estudaram o comportamento mecânico de um Argissolo e um Latossolo, respectivamente, submetidos a diferentes tipos de manejo. Na umidade correspondente ao ponto de murcha permanente, o solo sob mata apresentou valores de 22 e $141 \mathrm{kPa}$ para $\sigma_{\mathrm{p}}$ e RPL, respectivamente, ao passo que no tratamento 30 anos, com manejo de verão, o solo apresentou 48 e $1.135 \mathrm{kPa}$, respectivamente (Quadro 3). Esse comportamento poderia ser atribuído a maiores valores de umidade do ponto de murcha permanente (potencial mátrico de $-1.500 \mathrm{kPa}$ ) para a mata, em relação às áreas cultivadas (Figura 3). No entanto, quando a umidade do solo é padronizada em $0,05 \mathrm{~kg} \mathrm{~kg}^{-1}$ para todos os tratamentos, observam-se maiores valores de $\sigma_{\mathrm{p}} \mathrm{eRPL}$ à medida que se aumenta o tempo de cultivo (Figuras 1 e 2).

Essa diferença entre os tratamentos para o horizonte superficial parece também estar relacionada com o aumento da densidade (Quadro 4) e diminuição da porosidade total do solo (umidade volumétrica no potencial mátrico igual a zero) com o tempo de cultivo (Figura 3), o que contribuiu para o aumento da capacidade de suporte de carga e da resistência mecânica à penetração de raízes no solo, principalmente quando são comparados os solos das áreas cultivadas com os da mata.

Quadro 2. Coeficientes "a" e "b" das equações de regressão de $\sigma_{\mathrm{p}}$ e RPL em função da umidade gravimétrica (Ug), para a profundidade de 0 a 0,2 m de um Argissolo Amarelo distrocoeso cultivado com cana-de-açúcar

\begin{tabular}{|c|c|c|c|c|c|c|}
\hline \multirow{2}{*}{ Tratamento } & \multicolumn{3}{|c|}{$\sigma_{p}=10^{(a+b . U g)}$} & \multicolumn{3}{|c|}{$\mathrm{RPL}=10^{(\mathrm{a}+\mathrm{b} \cdot \mathrm{Ug})}$} \\
\hline & $\mathbf{a}$ & $\mathbf{b}$ & $\mathbf{R}^{2}$ & $\mathbf{a}$ & $\mathbf{b}$ & $\mathbf{R}^{2}$ \\
\hline Mata & 1,5060 & $-1,4972 * *$ & 0,6477 & 2,7309 & $-5,6596 * *$ & 0,5175 \\
\hline 4 anos I & 1,6234 & $-1,9174 * *$ & 0,5173 & 3,1391 & $-9,4768 * *$ & 0,7988 \\
\hline 14 anos I & 1,6554 & $-1,9670 * *$ & 0,5257 & 3,1189 & $-8,4506 * *$ & 0,7473 \\
\hline 14 anos V & 1,6654 & $-1,4684 * *$ & 0,3397 & 3,1388 & $-7,6336 * *$ & 0,5690 \\
\hline 30 anos I & 1,7786 & $-2,0917 * *$ & 0,6231 & 3,2619 & $-7,9581 * *$ & 0,7581 \\
\hline 30 anos V & 1,7782 & $-2,1084 * *$ & 0,5124 & 3,4928 & $-9,5190 * *$ & 0,7612 \\
\hline
\end{tabular}

**: significativo a $1 \%$ pelo teste de "t".

Quadro 3. Pressão de pré-compactação $(\sigma p)$ e resistência do solo à penetração em laboratório (RPL) para umidade gravimétrica (Ug) de saturação (Ugs) e ponto de murcha permanente (Ugpmp), na profundidade de 0 a 0,20 m de um Argissolo Amarelo distrocoeso cultivado com cana-de-açúcar

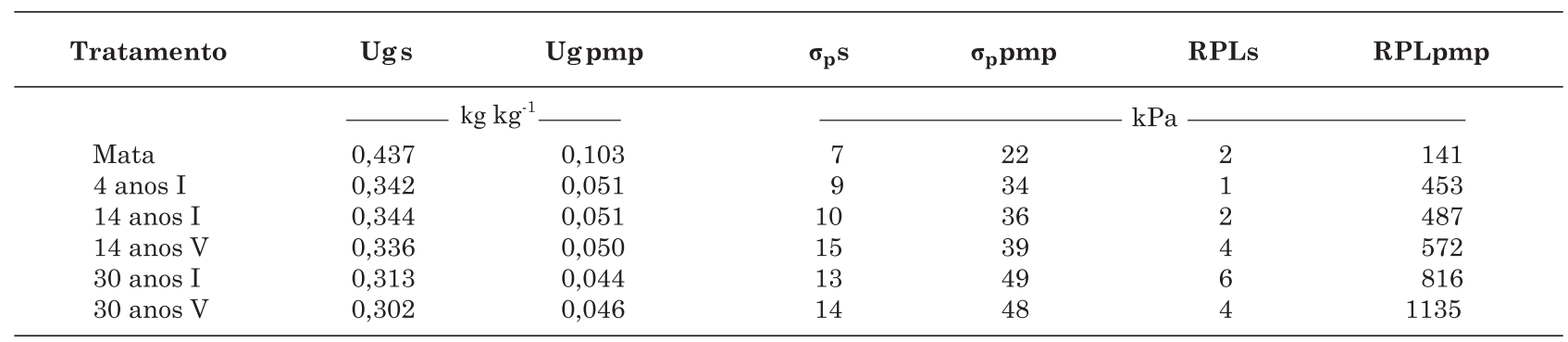




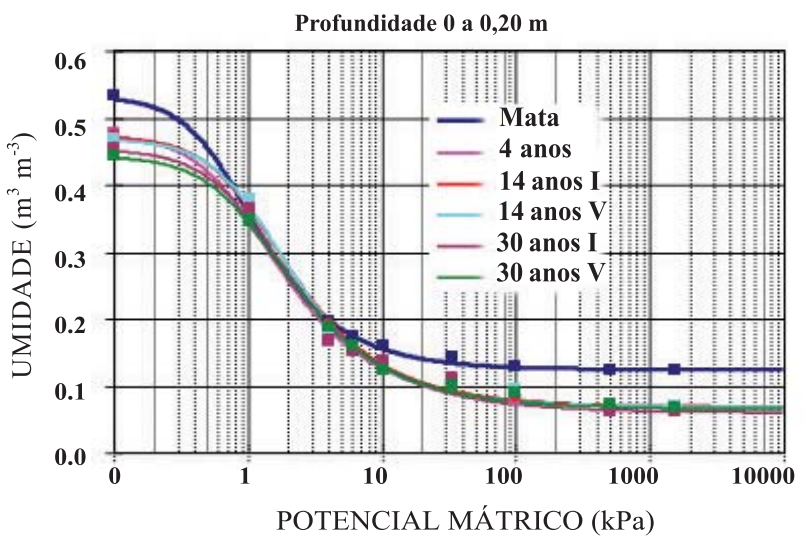

Figura 3. Curvas características de retenção de água para o solo dos seis tratamentos na profundidade de 0 a $0,20 \mathrm{~m}$.

O incremento da densidade do solo aumenta a fricção entre as partículas sólidas e a coesão no solo, que atuam como principais mecanismos para o aumento da resistência mecânica do solo à penetração (Vepraskas 1984) e, segundo Lebert \& Horn (1991), a resistência ao cisalhamento, que também é dependente da densidade e da umidade do solo. A densidade do solo altera o ângulo de atrito interno por estar relacionada ao arranjo espacial das partículas, que está diretamente relacionado com o número de pontos de contato entre estas; para um mesmo material, o atrito é tanto maior quanto maior for a densidade do solo e, consequentemente, maior quantidade de pontos de contato entre as partículas sólidas do solo.

Na profundidade de 0 a $0,20 \mathrm{~m}$, o Argissolo das áreas cultivadas apresentou maior resistência à penetração do que aquele sob a mata. Contudo, mesmo na umidade correspondente ao ponto de murcha permanente, o solo delas não atingiu valores maiores ou iguais a $2.000 \mathrm{kPa}$ (Quadro 3), que é considerado como limite crítico ao desenvolvimento do sistema radicular da maioria das culturas (Tormena et al., 1998; Lapen et al., 2004; Blainski et al., 2008).
Por se tratar de um horizonte arenoso, pode-se inferir que a resistência mecânica à penetração não é o fator limitante ao desenvolvimento de raízes nos primeiros $0,2 \mathrm{~m}$, e sim a disponibilidade de água. Portanto, nessa profundidade, o intervalo hídrico ótimo (IHO) passa a ser igual à água disponível (AD), que é a diferença entre a umidade da capacidade de campo $(\theta c c)$ e a umidade do ponto de murcha permanente $(\theta$ pmp), pois a $\theta$ pa é maior que a $\theta c c$, e a $\theta$ rp, menor que a $\theta$ pmp (Quadro 4).

O solo da mata apresentou $\theta c c$ maior do que o das áreas cultivadas e, provavelmente, por mostrar maior quantidade de matéria orgânica em decomposição, também apresentou maior $\theta \mathrm{pmp}$ (Figura 3 e Quadro 4). Essa característica de retenção de água conferiu ao solo da mata menor IHO. Assim, pode-se inferir que o cultivo da cana-de-açúcar favoreceu a disponibilidade de água nesse horizonte. Esse resultado converge com afirmações de Camargo (1983) e Dias Junior (2000), os quais afirmaram que um dos efeitos benéficos da compactação, até certo nível, pode ser atribuído ao aumento da disponibilidade de água em períodos mais secos, em razão do maior contato do solo com sementes ou raízes. Segundo Hill et al. (1985), o aumento da densidade do solo pode proporcionar maior quantidade de água disponível às plantas, porém esses efeitos variam com a granulometria e o teor de matéria orgânica no solo.

\section{Horizonte $\mathrm{AB}(0,2$ a $0,4 \mathrm{~m})$}

A compressibilidade e resistência mecânica à penetração do horizonte $\mathrm{AB}(0,2$ a $0,4 \mathrm{~m})$, para $\mathrm{o}$ Argissolo dos seis tratamentos, apresentou comportamento similar ao do horizonte superficial, porém com valores absolutos bem superiores, principalmente quando o solo apresentava umidades mais baixas (Figuras 4 e 5). Essa variação do comportamento mecânico com a profundidade é uma característica dos Argissolos, por apresentarem granulometria mais fina em profundidades maiores, o que aumenta a coesão entre as partículas sólidas.

Quadro 4. Densidade do solo (Ds), umidade do solo em que a porosidade de aeração é $\leq 0,1 \mathrm{~m}^{3} \mathrm{~m}^{-3}(\theta \mathrm{pa})$, umidade do solo na capacidade de campo $(\theta \mathrm{cc})$, umidade do solo no ponto de murcha permanente (qpmp), umidade do solo quando a resistência à penetração é $\geq 2000 \mathrm{kPa}(\theta \mathrm{rp})$ e intervalo hídrico ótimo (IHO), para os seis tratamentos na profundidade de 0 a $0,20 \mathrm{~m}$

\begin{tabular}{lcccccc}
\hline Tratamento & Ds & 0pa & Occ & 0pmp & Orp & IHO \\
\hline & Mg m & & & & & \\
& 1,21 & 0,428 & 0,156 & 0,125 & $* *$ & 0,031 \\
Mata & 1,38 & 0,372 & 0,126 & 0,070 & $* *$ & 0,056 \\
4 anos I & 1,37 & 0,371 & 0,133 & 0,070 & $* *$ & 0,063 \\
14 anos I & 1,39 & 0,367 & 0,128 & 0,070 & $* *$ & 0,058 \\
14 anos V & 1,44 & 0,351 & 0,129 & 0,063 & $* *$ & 0,066 \\
30 anos I & 1,46 & 0,341 & 0,130 & 0,067 & 0,029 & 0,063 \\
30 anos V & & &
\end{tabular}

**: tratamentos em que a RPL não atinge $2.000 \mathrm{kPa}$, mesmo com teor de umidade zero (obtido pela curva de RPL em função do teor de umidade). 


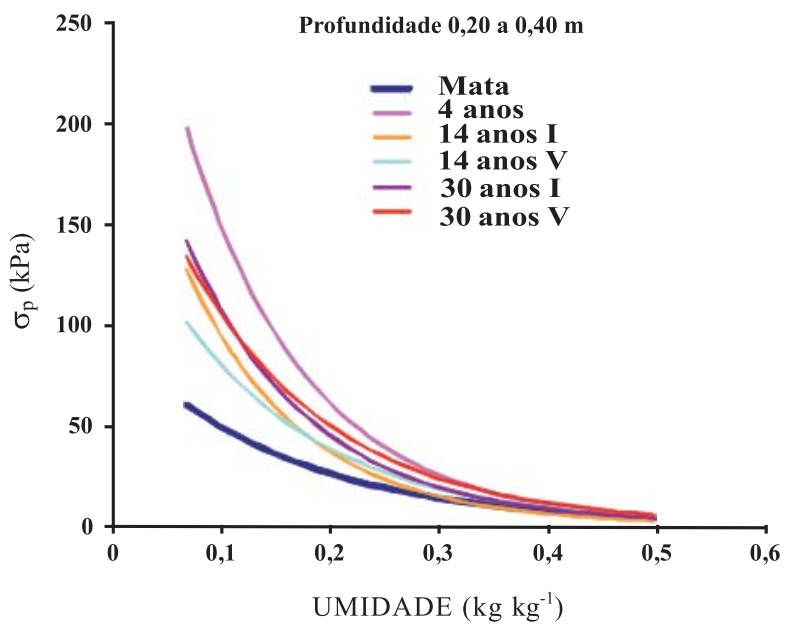

Figura 4. Pressão de pré-compactação $\left(\sigma_{p}\right)$ em função da umidade, na profundidade de 0,20 a $0,40 \mathrm{~m}$ de um Argissolo Amarelo distrocoeso cultivado com cana-de-açúcar: $\sigma_{\mathrm{p}}=10^{(\mathrm{a}+\mathrm{b} \cdot \mathrm{Ug})}$.

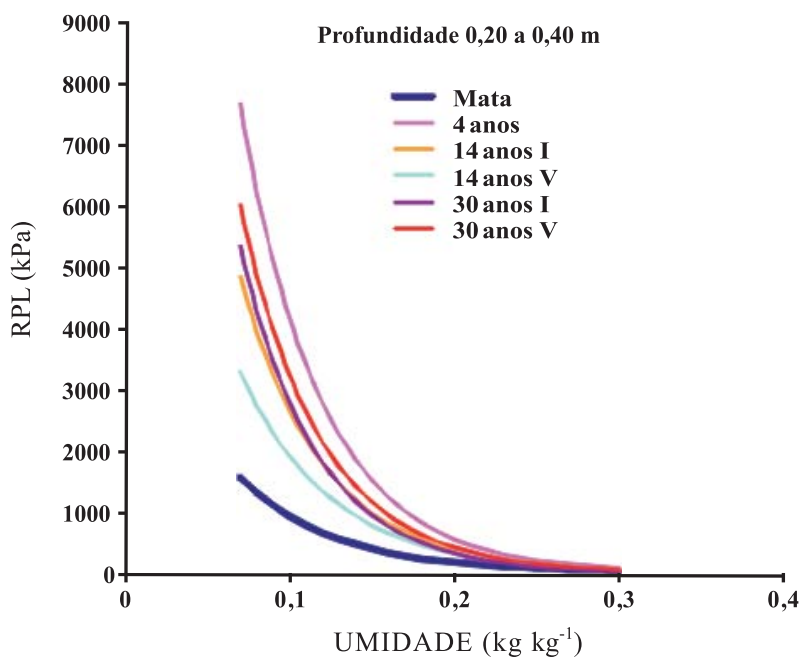

Figura 5. Resistência do solo à penetração em laboratório em função da umidade, na profundidade de 0,20 a 0,40 m de um Argissolo Amarelo distrocoeso cultivado com cana-deaçúcar: $\mathrm{RPL}=10^{(\mathrm{a}+\mathrm{b} \cdot \mathrm{Ug})}$.

O solo da mata apresentou menor $\sigma_{p}$ e RPL, em umidades mais baixas, quando comparado ao solo dos demais tratamentos, para a profundidade de 0,20 a 0,40 m (Figuras 4 e 5). Ao se compararem as cinco áreas cultivadas com cana-de-açúcar, não se observa tendência lógica do efeito do tempo e tipo de cultivo sobre $\sigma_{\mathrm{p}}$ eRPL do horizonte AB do Argissolo estudado, quando se esperava comportamento semelhante ao ocorrido na camada de 0 a $0,2 \mathrm{~m}$.

Na profundidade de 0,20 a 0,40 m, o solo da mata apresentou menor coeficiente linear e angular tanto para o modelo de $\sigma_{\mathrm{p}}$ quanto para o de RPL, quando comparado com o solo dos tratamentos das áreas cultivadas com cana-de-açúcar (Quadro 5). A maior pressão de pré-compactação do solo das áreas cultivadas é reflexo do histórico de pressões externas sofridas devido ao uso do solo, conforme sugerido por Dias Junior, (1994), Dias Junior \& Pearce (1996), Kondo \& Dias Junior (1999) e Silva et al. (1999).

A compactação causada por modificação no ciclo de umedecimento e secagem, tráfego de máquinas na colheita e tratos culturais, bem como a ação dos órgãos ativos dos equipamentos de cultivo, logo nos primeiros anos de exploração com cana-de-açúcar (4 anos I), parece ter aumentado a $\sigma_{\mathrm{p}}$ do horizonte $\mathrm{AB}$ até níveis suficientes para suportar pressões atualmente aplicadas por máquinas na Usina Coruripe.

Por mais de 18 anos o sistema de colheita com "transbordo", que usa pneus de "alta flutuação", pode ter contribuído para evitar compactações adicionais em camadas mais profundas do solo. Essa poderia ser uma explicação para a pequena diferença entre os coeficientes lineares e angulares das equações de $\sigma_{\mathrm{p}} \mathrm{e}$ RPL referentes às áreas cultivadas por 14 e 30 anos, em relação à área cultivada por quatro anos (Quadro 5). Provavelmente, a maior $\sigma_{\mathrm{p}}$ e RPL do solo da área de quatro anos em relação às demais áreas cultivadas pode ser atribuída ao maior teor de argila no horizonte AB (Quadro 1). No entanto, acredita-se que essa diferença na textura não tenha comprometido a qualidade dos resultados.

Considerando o uso de "transbordo" e que as áreas cultivadas com cana-de-açúcar apresentavam-se no mesmo ciclo de cultivo (quarto corte), pode-se inferir que os níveis de compactação observados no horizonte AB, provavelmente, não estão sendo estabelecidos pela operação de colheita, e sim pelas operações de tratos culturais, em que os pneus e órgãos ativos das máquinas concentram as pressões nas entrelinhas, o que pode diminuir os efeitos da subsolagem e adubação verde a cada ciclo de cultivo.

Portanto, seria necessário um estudo para avaliar a evolução da pressão de pré-compactação e resistência do solo à penetração em horizontes subsuperficiais, desde a implantação da lavoura até renovação, com o objetivo de verificar a atenuação do efeito da subsolagem. Os resultados poderiam ser de grande utilidade na tomada de decisão sobre a necessidade da operação de subsolagem, bem como no uso da modelagem de $\sigma_{\mathrm{p}}$ e RPL para auxiliar na determinação do momento ideal para renovação das lavoras de canade-açúcar.

A pressão na superfície do solo por trânsito de máquinas, mesmo sendo transmitida de forma atenuada para horizontes mais profundos, muitas vezes é aplicada ao solo com umidades favoráveis à compactação subsuperficial, ou seja, subsolo com capacidade de suporte de carga $\left(\sigma_{p}\right)$ menor do que a pressão aplicada durante operações mecanizadas.

A pressão média que um pneu exerce sobre a superfície do solo é aproximadamente a sua pressão de inflação, quando esta é a indicada pelo fabricante 
Quadro 5. Coeficientes "a" e "b" das equações de regressão de $\sigma_{p}$ e RPL em função da umidade gravimétrica (Ug), para a profundidade de 0,20 a 0,40 m de um Argissolo Amarelo distrocoeso cultivado com cana-deaçúcar

\begin{tabular}{|c|c|c|c|c|c|c|}
\hline \multirow{2}{*}{ Tratamento } & \multicolumn{3}{|c|}{$\sigma_{p}=10^{(a+b . U g)}$} & \multicolumn{3}{|c|}{$\mathrm{RPL}=10^{(\mathrm{a}+\mathrm{b} . \mathrm{Ug})}$} \\
\hline & $\mathbf{a}$ & $\mathbf{b}$ & $\mathbf{R}^{2}$ & $\mathbf{a}$ & $\mathbf{b}$ & $\mathbf{R}^{2}$ \\
\hline Mata & 1,9695 & $-2,7779 * *$ & 0,6292 & 3,7170 & $-7,5570 * *$ & 0,7194 \\
\hline 4 anos I & 2,5640 & $-3,8919 * *$ & 0,6248 & 4,5003 & $-8,8183 * *$ & 0,5840 \\
\hline $14 \operatorname{anos} I$ & 2,3894 & $-4,1283 * *$ & 0,6946 & 4,2902 & $-8,6598 * *$ & 0,6632 \\
\hline 14 anos V & 2,2189 & $-3,1337 * *$ & 0,5335 & 4,0623 & $-7,8315 * *$ & 0,6033 \\
\hline 30 anos I & 2,4146 & $-3,8256 * *$ & 0,6883 & 4,3821 & $-9,3790 * *$ & 0,6971 \\
\hline 30 anos $\mathrm{V}$ & 2,3517 & $-3,2666$ ** & 0,6086 & 4,4046 & $-8,9618 * *$ & 0,6885 \\
\hline
\end{tabular}

**: significativo a $1 \%$ pelo teste de "t".

do pneu (Arvidsson \& Keller, 2007). No entanto, esses autores verificaram pressões a $0,1 \mathrm{~m}$ de profundidade, até 39 \% mais altas que a pressão de inflação dos pneus, principalmente em cargas, sobre os rodados, mais altas. Também verificaram que a partir de $0,3 \mathrm{~m}$ de profundidade a variação da pressão de inflação teve pouca influência, considerando cargas constantes. Contudo, constataram que a variação da carga sobre as rodas teve influência muito grande nas pressões aplicadas em camadas subsuperficiais, sendo observadas, para uma carga de $3.300 \mathrm{kgf}$, pressões de 164,159 e $135 \mathrm{kPa}$ na profundidade de 0,30 m, quando a pressão de inflação era de 150, 100 e 70 kPa, o que seria suficiente para ultrapassar a capacidade de suporte de carga $\left(\sigma_{\mathrm{p}}\right)$ do horizonte AB do Argissolo estudado, na sua condição natural (mata), mesmo para umidades muito baixas (Figura 4).

Pressões de 50 a $60 \mathrm{kPa}$ aplicadas ao horizonte AB da mata, contendo umidade próxima à da capacidade de campo, podem ter originado compactação, reduzindo a porosidade natural do solo da mata de $0,45 \mathrm{~m}^{3} \mathrm{~m}^{-3}$ para aproximadamente $0,40 \mathrm{~m}^{3} \mathrm{~m}^{-3}$ (Figura 6). Essa compactação aumentou a $\sigma_{\mathrm{p}}$ e RPL

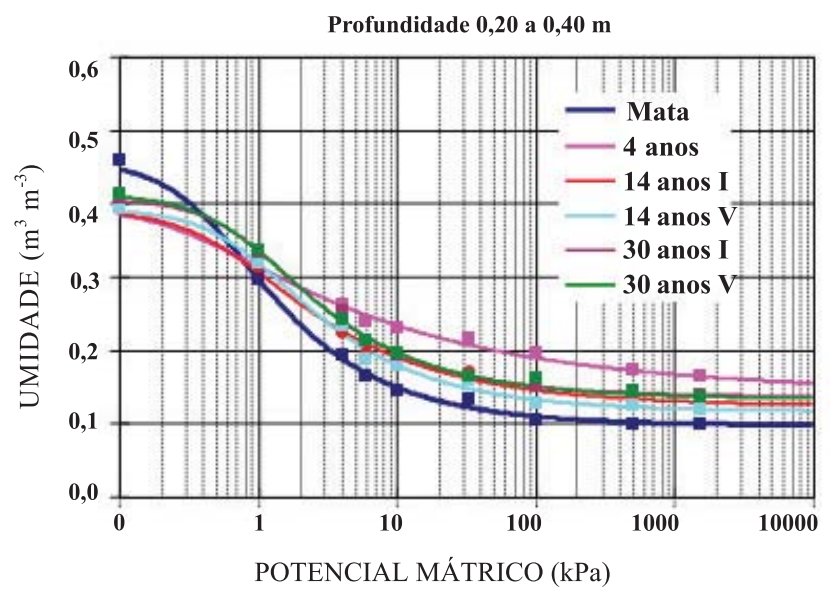

Figura 6. Curvas características de retenção de água para o solo dos seis tratamentos na profundidade de 0,20 a $0,40 \mathrm{~m}$. das áreas cultivadas para valores médios acima de 100 e $3.000 \mathrm{kPa}$, respectivamente, quando o solo, nessa profundidade, apresentou umidade correspondente ao ponto de murcha permanente (Quadro 6).

Mesmo para a umidade de saturação, as áreas cultivadas apresentaram maiores $\sigma_{\mathrm{p}}$ e RPL em relação à mata (Quadro 6). Esse resultado demonstra o maior atrito interno entre as partículas no horizonte $\mathrm{AB}$ do solo das áreas cultivadas, que apresentaram densidade entre 1,53 e $1,58 \mathrm{Mg} \mathrm{m}^{-3}$, contra $1,41 \mathrm{Mg} \mathrm{m}^{-3}$ da área de mata (Quadro 7).

Na umidade correspondente ao ponto de murcha permanente, o horizonte $\mathrm{AB}$ do solo sob mata apresentou RPLigual a $1.515 \mathrm{kPa}$ (Quadro 6), ou seja, inferior ao limite de $2.000 \mathrm{kPa}$, considerado como crítico ao desenvolvimento radicular da maioria das culturas (Blainski et al., 2008). No quadro 7, observase que o solo da mata apresentou umidade muito inferior em relação ao das áreas cultivadas para que a RPL fosse maior ou igual a $2.000 \mathrm{kPa}(\theta \mathrm{rp})$. Essa característica confere ao horizonte $\mathrm{AB}$ do solo da mata capacidade de manter baixas resistências à penetração mesmo com umidade abaixo do ponto de murcha permanente. Portanto, considerando também que a $\theta$ pa foi maior que a $\theta \mathrm{cc}$, o IHO do horizonte $\mathrm{AB}$ do solo da mata é igual à água disponível, ou seja, $0,050 \mathrm{~m}^{3} \mathrm{~m}^{-3}$ (Quadro 7). O solo das áreas cultivadas apresentou RPL bem acima de $2.000 \mathrm{kPa}$ na umidade do ponto de murcha permanente, para o horizonte $\mathrm{AB}$ (Quadro 6). Nessas áreas, mesmo havendo umidade no solo acima do ponto de murcha permanente para desenvolvimento de raízes, a resistência à penetração torna-se restritiva ao crescimento radicular; assim, o IHO é menor do que a $\mathrm{AD}$, ou seja, é o volume de água contido entre a $\theta$ rp e a $\theta$ cc. O solo das áreas cultivadas apresentou IHO variando de 0,010 a $0,026 \mathrm{~m}^{3} \mathrm{~m}^{-3}$, que é bem inferior quando comparado com o IHO do horizonte $\mathrm{AB}$ do solo sob mata nativa (Quadro 7).

Segundo Cavalieri et al. (2006), o IHO aprimora o tradicional conceito de água disponível entre capacidade de campo (CC) e ponto de murcha permanente (PMP), adicionando as limitações 
Quadro 6. Pressão de pré-compactação $(\sigma p)$ e resistência do solo à penetração em laboratório (RPL) para umidade gravimétrica de saturação (Ugs) e ponto de murcha permanente (Ugpmp), na profundidade de 0,20 a 0,40 m de um Argissolo Amarelo distrocoeso cultivado com cana-de-açúcar

\begin{tabular}{|c|c|c|c|c|c|c|}
\hline Tratamento & Ugs & Ug pmp & $\sigma_{\mathrm{p}} \mathrm{s}$ & $\sigma_{\mathrm{p}} \mathbf{p m p}$ & RPLs & RPLpmp \\
\hline & \multicolumn{2}{|c|}{$\mathrm{kg} \mathrm{kg}^{-1}$} & \multicolumn{4}{|c|}{$-\mathrm{kPa}$} \\
\hline Mata & 0,317 & 0,071 & 12 & 59 & 21 & 1515 \\
\hline 4 anos I & 0,244 & 0,106 & 41 & 142 & 223 & 3678 \\
\hline 14 anos I & 0,244 & 0,082 & 24 & 112 & 150 & 3803 \\
\hline 14 anos V & 0,247 & 0,076 & 28 & 96 & 134 & 2932 \\
\hline 30 anos I & 0,261 & 0,090 & 26 & 118 & 86 & 3451 \\
\hline 30 anos V & 0,268 & 0,090 & 30 & 114 & 101 & 3963 \\
\hline
\end{tabular}

Quadro 7. Densidade do solo (Ds), umidade do solo em que a porosidade de aeração é $\leq 0,1 \mathrm{~m}^{3} \mathrm{~m}^{-3}(\theta \mathrm{pa})$, umidade do solo na capacidade de campo $(\theta \mathrm{cc})$, umidade do solo no ponto de murcha permanente $(\theta \mathrm{pmp})$, umidade do solo quando a resistência à penetração é $\geq 2000 \mathrm{kPa}(\theta \mathrm{rp})$ e intervalo hídrico ótimo (IHO), para os seis tratamentos na profundidade de 0,20 a $0,40 \mathrm{~m}$

\begin{tabular}{|c|c|c|c|c|c|c|}
\hline Tratamento & Ds & $\theta$ pa & $\theta$ cc & $\theta$ pmp & $\theta \mathbf{r p}$ & IHO \\
\hline & $\mathrm{Mg} \mathrm{m}^{-3}$ & & & $\mathrm{~m}^{3} \mathrm{~m}^{-3}$ & & \\
\hline Mata & 1,41 & 0,347 & 0,150 & 0,100 & 0,078 & 0,050 \\
\hline 4 anos I & 1,58 & 0,286 & 0,234 & 0,167 & 0,215 & 0,019 \\
\hline $14 \operatorname{anos} I$ & 1,58 & 0,286 & 0,191 & 0,130 & 0,180 & 0,011 \\
\hline 14 anos V & 1,58 & 0,290 & 0,180 & 0,120 & 0,154 & 0,026 \\
\hline 30 anos I & 1,55 & 0,304 & 0,197 & 0,140 & 0,179 & 0,018 \\
\hline $30 \operatorname{anos} \mathrm{V}$ & 1,53 & 0,309 & 0,198 & 0,137 & 0,188 & 0,010 \\
\hline
\end{tabular}

associadas com a aeração e resistência à penetração. Nos solos em que os sistemas de manejo propiciam melhoria da sua qualidade estrutural, o IHO é numericamente igual a $\mathrm{AD}$. Por outro lado, em situações de degradação estrutural, percebe-se redução na porosidade total, bem como alterações na distribuição do tamanho dos poros. Isso implica valores de porosidade com ar de pelo menos $0,1 \mathrm{~m}^{3} \mathrm{~m}^{-3}$ em teores de água inferiores a CC, enquanto teores de água não restritivos à resistência à penetração são superiores ao ponto de murcha permanente. Nesses casos, o IHO tem seus limites superior e inferior estabelecidos pela umidade referente à porosidade de aeração $(\theta p a)$ e resistência do solo à penetração $\geq 2.000 \mathrm{kPa}(\theta \mathrm{rp})$, respectivamente, podendo ser considerada a pior situação possível.

Como o solo das áreas cultivadas apresentou $\theta$ pa superior ao $\theta c c$, pode-se inferir que o horizonte $\mathrm{AB}$ do Argissolo das áreas cultivadas encontra-se em uma situação intermediária de degradação, o que pode ser agravado pela combinação do caráter coeso com pressões aplicadas acima da capacidade de carga, para uma determinada umidade.

\section{Horizonte Bt $(0,40$ a $0,60 \mathrm{~m})$}

Para o horizonte Bt (0,40 a 0,60 m), observa-se que os modelos de $\sigma_{p}$, em função da umidade, não apresentam tendências muito claras na diferenciação dos solos dos tratamentos referentes às áreas cultivadas (Figura 7). Esse resultado é esperado quando se compara o horizonte Bt com os horizontes mais superficiais. Isso provavelmente ocorreu devido à atenuação das pressões aplicadas na superfície, em relação às camadas mais profundas do perfil do solo. No entanto, a curva de $\sigma_{\mathrm{p}}$ do horizonte Bt do solo da mata mostrou comportamento diferenciado, apresentando valores menores para umidades do solo mais baixas, indicando compactação mesmo em camadas mais profundas (Figura 7). Pode-se observar que o horizonte Bt do solo na mata apresentou coeficientes de ajuste "a" e "b" inferiores, para o modelo de $\sigma_{\mathrm{p}}$, quando comparado com o mesmo horizonte do solo das áreas cultivadas (Quadro 8), indicando pequeno aumento na capacidade de suporte de carga na profundidade de 0,40 a $0,60 \mathrm{~m}$, devido ao desmatamento e à mecanização das áreas para o cultivo com cana-de-açúcar.

Para a RPL do horizonte Bt, a curva referente à condição de uso da mata também ficou isolada em relação aos demais tratamentos (Figura 8); na mata, apresentou menor resistência à penetração para umidades mais baixas (Quadro 9). No entanto, o solo das áreas cultivadas teve tendência de apresentar menores coeficientes angulares para os modelos de RPL em função da umidade, com exceção do tratamento 14 anos I (Quadro 8). 
Aumento da capacidade de suporte de carga $\left(\sigma_{\mathrm{p}}\right) \mathrm{e}$ menor inclinação da curva de RPL são desejáveis, por conferirem ao solo capacidade de suportar maiores pressões externas, sem restringir a capacidade de

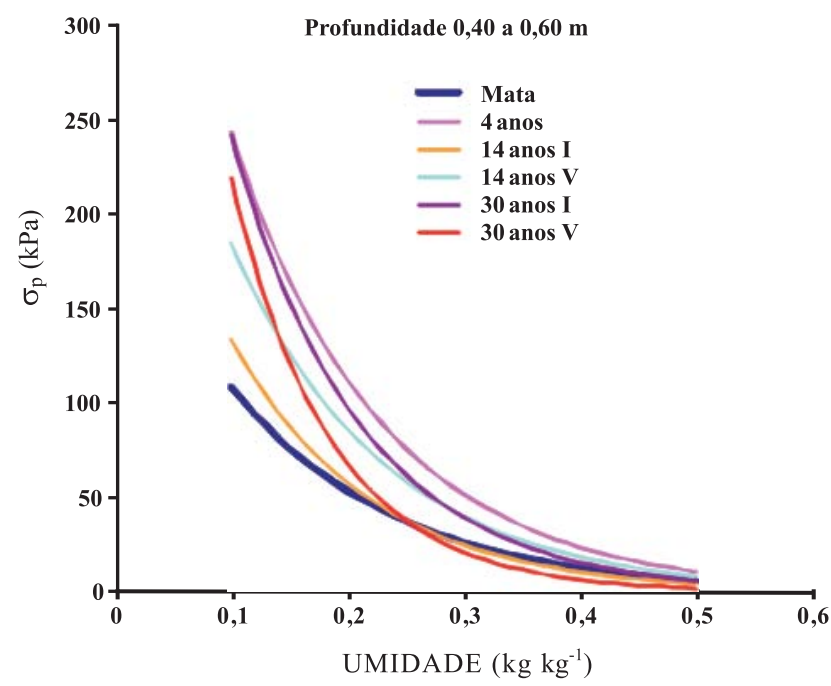

Figura 7. Pressão de pré-compactação $\left(\sigma_{p}\right)$ em função da umidade, na profundidade de 0,40 a $0,60 \mathrm{~m}$ de um Argissolo Amarelo distrocoeso cultivado com cana-de-açúcar: $\sigma_{\mathrm{p}}=10^{(\mathrm{a}+\mathrm{b} \cdot \mathrm{Ug})}$. penetração de raízes. Esse tipo de comportamento mecânico pode ser atribuído à operação de subsolagem, que tem o objetivo de quebrar camadas compactadas devido à mecanização agrícola ou adensadas naturalmente. Segundo Rezende (2000), o subsolador é uma boa alternativa para contornar o problema da coesão, por se tratar de implemento de ação profunda no solo por meio de órgãos ativos - as hastes, que não revolvem o solo, apenas o movimentam de forma a manter sua ordem natural.

Efeitos favoráveis da subsolagem no ambiente de Tabuleiros Costeiros foram citados por Nacif (1994), que observou aumento de porosidade total e macroporosidade, menor compacidade e melhor armazenamento de água no solo. Resultados convergentes foram obtidos por Xu \& Mermoud (2001), observando que a subsolagem causou importante redução na densidade nos primeiros $0,40 \mathrm{~m}$ do perfil do solo, aumento significativo do volume de macroporos e decréscimo no volume de microporos, promovendo melhoria na condutividade hidráulica do solo.

Galvão (2002), estudando os efeitos de diferentes sistemas de preparo de um Argissolo na Usina Coruripe, concluiu que a subsolagem proporcionou melhoria na compacidade do solo, aumentou a taxa de infiltração da água no solo e proporcionou aumento na produtividade da cana-de-açúcar.

Quadro 8. Coeficientes “a” e "b" das equações de regressão de $\sigma_{p}$ e RPL em função da umidade gravimétrica (Ug), para a profundidade de 0,40 a 0,60 m de um Argissolo Amarelo distrocoeso cultivado com cana-deaçúcar

\begin{tabular}{|c|c|c|c|c|c|c|}
\hline \multirow{2}{*}{ Tratamento } & \multicolumn{3}{|c|}{$\sigma_{p}=10^{(a+b . U g)}$} & \multicolumn{3}{|c|}{$\mathrm{RPL}=10^{(\mathrm{a}+\mathrm{b} \cdot \mathrm{Ug})}$} \\
\hline & $\mathbf{a}$ & $\mathbf{b}$ & $\mathbf{R}^{2}$ & $\mathbf{a}$ & $\mathbf{b}$ & $\mathrm{R}^{2}$ \\
\hline Mata & 2,3405 & $-3,0196 * *$ & 0,4353 & 4,4044 & $-8,3045 * *$ & 0,5815 \\
\hline 4 anos I & 2,7209 & $-3,3387 * *$ & 0,7133 & 4,7698 & $-8,0532 * *$ & 0,7402 \\
\hline 14 anos I & 2,4888 & $-3,6033 * *$ & 0,6460 & 4,7052 & $-8,6883 * *$ & 0,7889 \\
\hline 14 anos V & 2,5974 & $-3,2917 * *$ & 0,5446 & 4,2576 & $-5,7431 * *$ & 0,5139 \\
\hline 30 anos I & 2,7730 & $-3,8931 * *$ & 0,6934 & 4,4386 & $-6,7772 * *$ & 0,6724 \\
\hline $30 \operatorname{anos} \mathrm{V}$ & 2,8465 & $-5,0524 * *$ & 0,6655 & 4,5954 & $-7,6684 * *$ & 0,6910 \\
\hline
\end{tabular}

**: significativo a $1 \%$ pelo teste de "t".

Quadro 9. Pressão de pré-compactação $(\sigma p)$ e resistência do solo à penetração em laboratório (RPL) para umidade gravimétrica de saturação (Ugs) e ponto de murcha permanente (Ugpmp), na profundidade de 0,40 a 0,60 m de um Argissolo Amarelo distrocoeso cultivado com cana-de-açúcar

\begin{tabular}{|c|c|c|c|c|c|c|}
\hline Tratamento & Ugs & Ug pmp & $\sigma_{p} s$ & $\sigma_{\mathrm{p}} \mathrm{pmp}$ & RPLs & RPLpmp \\
\hline & \multicolumn{2}{|c|}{$\mathrm{kg} \mathrm{kg}^{-1}$} & & 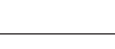 & & - \\
\hline Mata & 0,328 & 0,112 & 22 & 101 & 48 & 2981 \\
\hline 4 anos I & 0,293 & 0,132 & 55 & 191 & 259 & 5091 \\
\hline 14 anos I & 0,329 & 0,124 & 20 & 110 & 70 & 4245 \\
\hline 14 anos V & 0,292 & 0,129 & 43 & 149 & 381 & 3287 \\
\hline 30 anos I & 0,290 & 0,136 & 44 & 175 & 297 & 3288 \\
\hline 30 anos V & 0,320 & 0,135 & 17 & 146 & 139 & 3632 \\
\hline
\end{tabular}




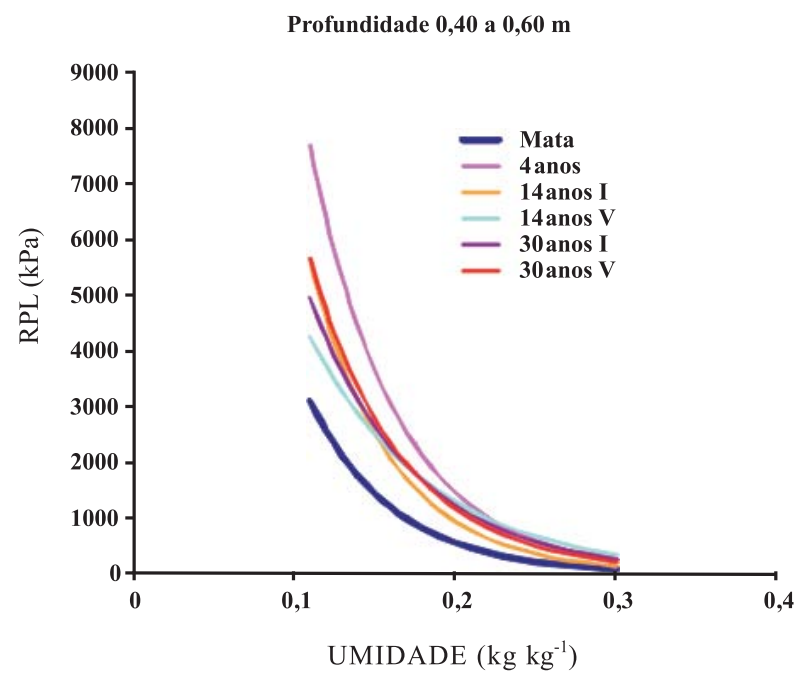

Figura 8. Resistência do solo à penetração em laboratório em função da umidade, na profundidade de 0,40 a 0,60 m de um Argissolo Amarelo distrocoeso cultivado com cana-deaçúcar: $\mathrm{RPL}=10^{(\mathrm{a}+\mathrm{b} \cdot \mathrm{Ug})}$.

Em hipótese, esperava-se uma resistência à penetração menor no horizonte Bt do solo nas áreas cultivadas em relação ao da mata, em detrimento da subsolagem. Todavia, considerando que essa operação é realizada na ocasião da renovação dos canaviais e que as lavouras apresentavam-se no quarto corte, acredita-se que o efeito da operação de subsolagem já estava atenuado, devido às pressões e vibrações exercidas durante as colheitas e tratos culturais.

Por meio da análise da curva característica de retenção de água (Figura 9), observa-se que o horizonte Bt do solo da mata apresentou porosidade total similar à dos demais tratamentos, bem como pequena diferença na Ds (Quadro 10). No entanto, o solo das áreas cultivadas apresentou maior retenção de água a partir de potenciais mais negativos que $-4 \mathrm{kPa}$, ou seja, maior porcentagem de microporos. A maior inflexão da curva característica de retenção de água no solo da mata representa maior porcentagem de macroporos na profundidade de 0,40 a $0,60 \mathrm{~m}$ para essa condição de uso, em relação ao solo das áreas cultivadas (Figura 9). Assim, a distribuição do tamanho de poros pode explicar a maior compressibilidade do horizonte Bt do solo da mata em valores de umidade mais baixos (Quadro 9), bem como o menor valor de umidade para que a resistência do solo à penetração seja $\geq 2000 \mathrm{kPa}$ (Quadro 10), quando comparado com o solo das áreas cultivadas.

Por apresentar $\theta$ rp maior do que $\theta \mathrm{pmp}$, o solo dos seis tratamentos teve o IHO definido entre os limites superiores e inferiores igual ao $\theta c c$ e $\theta \mathrm{rp}$, respectivamente, tendo seus valores de IHO inferiores a AD (Quadro 10). Para as áreas cultivadas, a umidade do solo que restringe a penetração de raízes ( $\theta \mathrm{rp}$ ) ficou muito próxima à umidade do solo na capacidade de campo ( $\theta c c)$; consequentemente, o solo desses tratamentos apresentou IHO, aproximadamente, três vezes menor do que o horizonte Bt do Argissolo sob mata nativa.

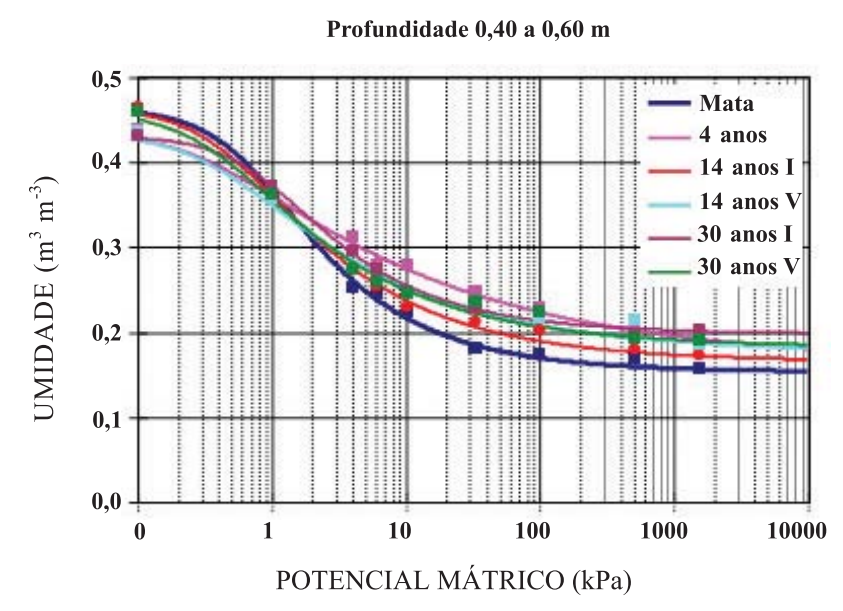

Figura 9. Curvas características de retenção de água para o solo dos seis tratamentos na profundidade de 0,40 a $0,60 \mathrm{~m}$.

Quadro 10. Densidade do solo (Ds), umidade do solo em que a porosidade de aeração é $\leq 0,1 \mathrm{~m}^{3} \mathrm{~m}^{-3}(\theta \mathrm{pa})$, umidade do solo na capacidade de campo $(\theta \mathrm{cc})$, umidade do solo no ponto de murcha permanente $(\theta \mathrm{pmp})$, umidade do solo quando a resistência à penetração é $\geq 2.000 \mathrm{kPa}(\theta \mathrm{rp})$ e intervalo hídrico ótimo (IHO), para os seis tratamentos na profundidade de 0,40 a $0,60 \mathrm{~m}$

\begin{tabular}{|c|c|c|c|c|c|c|}
\hline Tratamento & Ds & $\theta$ pa & $\theta c c$ & $\theta$ pmp & $\theta \mathbf{r p}$ & IHO \\
\hline & $\mathrm{Mg} \mathrm{m}^{-3}$ & & & $\mathrm{~m}^{3} \mathrm{~m}^{-3}$ & & \\
\hline Mata & 1,40 & 0,359 & 0,217 & 0,157 & 0,186 & 0,031 \\
\hline 4 anos I & 1,46 & 0,327 & 0,275 & 0,193 & 0,266 & 0,009 \\
\hline $14 \operatorname{anos} \mathrm{I}$ & 1,39 & 0,358 & 0,238 & 0,173 & 0,225 & 0,013 \\
\hline 14 anos V & 1,46 & 0,327 & 0,254 & 0,188 & 0,243 & 0,011 \\
\hline 30 anos I & 1,48 & 0,329 & 0,257 & 0,202 & 0,248 & 0,009 \\
\hline 30 anos $\mathrm{V}$ & 1,41 & 0,351 & 0,250 & 0,190 & 0,238 & 0,012 \\
\hline
\end{tabular}




\section{CONCLUSÕES}

1. Os horizontes $\mathrm{Ap}, \mathrm{AB}$ e Bt do Argissolo Amarelo das áreas cultivadas com cana-de-açúcar apresentaram maior pressão de pré-compactação e resistência à penetração do que o Argissolo sob mata nativa, principalmente para umidades mais baixas.

2. O trânsito de máquinas agrícolas para cultivo da cana-de-açúcar não aumentou a resistência à penetração do horizonte Ap do Argissolo Amarelo até níveis que possam ser considerados críticos, mesmo para umidade referente ao ponto de murcha permanente.

3. O cultivo com cana-de-açúcar aumentou o intervalo hídrico ótimo (IHO) do horizonte superficial do Argissolo Amarelo.

4. O cultivo com cana-de-açúcar elevou a resistência à penetração dos horizontes $\mathrm{AB}$ e $\mathrm{Bt}$ do Argissolo estudado até nível crítico ao desenvolvimento de raízes, em umidade pouco abaixo à da capacidade de campo.

5. As operações mecanizadas para o cultivo da cana-de-açúcar reduziram o IHO dos horizontes $\mathrm{AB}$ e Bt do Argissolo de Tabuleiros Costeiros.

6. A pressão de pré-compactação deve ser usada como capacidade de suporte de carga no planejamento de operações mecanizadas em lavouras de cana-deaçúcar, com o objetivo de evitar a degradação física de horizontes subsuperficiais de Argissolos Amarelos distrocoesos dos Tabuleiros Costeiros de Alagoas.

\section{AGRADECIMENTOS}

À Usina Coruripe, pela disponibilização das áreas e pelo apoio logístico.

\section{LITERATURA CITADA}

ASSOCIAÇÃO BRASILEIRA DE NORMAS TECNICAS . ABNT. Ensaio de adensamento unidimensional. ABNT. - NBR 12007. Rio de Janeiro, 1990. 13p.

ARVIDSSON, J. \& KELLER, T. Soil stress as affected by wheel load and tyre inflation pressure, Soil Tillage Res., 96:284-291, 2007.

BLAINSKI, E.; TORMENA, C.A.; FIDALSKI, J. \& GUIMARÃES, R.M.L. Quantificação da degradação física do solo por meio da curva de resistência do solo à penetração. R. Bras. Ci. Solo, 32:975-983, 2008.

CAMARGO, O.A. Compactação do solo e desenvolvimento de plantas. Campinas, Fundação Cargill, 1983. 44p.
CAVALIERI, K.M.V.; TORMENA, C.A.; VIDIGAL FILHO, P.S.; GONÇALVES, A.C.A. \& COSTA, A.C. Efeito de sistemas de preparo nas propriedades físicas de um Latossolo Vermelho distroférrico. R. Bras. Ci. Solo, 30:137-147, 2006.

DIAS JUNIOR, M.S. Compression of three soils under longterm tillage and wheel traffic. East Lansing, Michigan State University, 1994. 114p. (Tese de Doutorado)

DIAS JUNIOR, M.S. Compactação do solo. In: NOVAIS, R.F.; ALVAREZ, V.H.V. \& SCHAEFER,. C.E.G.R. Tópicos em ciência do solo. Viçosa, MG, Sociedade Brasileira de Ciência do Solo, 2000. v.1. p.56-94.

DIAS JUNIOR, M.S. \& PIERCE, F.J. Revisão de literatura: O processo de compactação do solo e sua modelagem. R. Bras. Ci. Solo, 20:175-182, 1996.

EMPRESA BRASILEIRA DE PESQUISA AGROPECUÁRIA EMBRAPA. Centro Nacional de Pesquisa do Solo. Manual de métodos de análise de solo. 2.ed. Rio de Janeiro, 1997. 212p.

EMPRESA BRASILEIRA DE PESQUISA AGROPECUÁRIA EMBRAPA. Centro Nacional de Pesquisa do Solo. Sistema brasileiro de classificação de solos. 2.ed. Rio de Janeiro, 2006. 300p.

GALVÃO, A.S. Rendimento de cana-de-açúcar e alguns atributos físicos de um Argissolo afetado pelo sistema de preparo do solo. Maceió, Universidade Federal de Alagoas, 2002. 75p. (Tese de Mestrado)

HILL, R.L.; HORTON, R. \& CRUSE, M.R. Tillage effects on soil water retention and pore size distribution of two Mollisols. Soil Sci. Soc. Am. J., 49:1264-1270, 1985.

HILLEL, D. Fundamentals of soil physics. New York, Academic Press, 1980. 413p.

JACOMINI, P.K.T.; CAVALCANTI, A.C.; PESSOA, S.C.P. \& SILVEIRA, C.O. Levantamento exploratório. Reconhecimento de solos do Estado de Alagoas. Recife, Centro de Pesquisas Pedológicas, 1975. 531p. (Boletim Técnico, 35)

KONDO, M.K. \& DIAS JUNIOR, M.S. Compressibilidade de três Latossolos em função da umidade e uso. R. Bras. Ci. Solo, 23:211-218, 1999.

LAPEN, D.R.; TOPP, G.C.; GREGORICH, E.G.; CURNOE, W.E. Least limiting water range indicators of soil quality and corn production. Soil \& Tillage Research, v.78, p.151170, 2004

LEBERT, M. \& HORN, R. A method to predict the mechanical strenght of agricultural soils. Soil Tillage Res., 19:275286, 1991.

LIMA, C.L.R. \& SILVA, A.P. Estimativa da capacidade de suporte de carga do solo a partir da avaliação da resistência à penetração. R. Bras. Ci. Solo, 30-2:217-223, 2006.

NACIF, P.G.S. Efeitos da subsolagem em propriedades fisicohídricas de um Latossolo Amarelo Álico coeso representativo do recôncavo baiano. Viçosa, MG, Universidade Federal de Viçosa, 1994. 75p. (Tese de Mestrado) 
OLIVEIRA, V.S. Compactação dos solos coesos dos Tabuleiros Costeiros de Alagoas. Recife, Universidade Federal Rural de Pernambuco, 2008. 81p. (Tese de Doutorado)

PACHECO, E.P. Estudo da compressibilidade e qualidade de um Argissolo Amarelo cultivado com cana-de-açúcar nos Tabuleiros Costeiros de Alagoas. Recife, Universidade Federal Rural de Pernambuco, 2010. 106p. (Tese de Doutorado)

REINERT, D.J.; ROBAINA, A. \& REICHERT, J.M. Compress - software e proposta de modelo para descrever a compressibilidade dos solos e seus parâmetros. In: CONGRESSO BRASILEIRO DE CIÊNCIA DO SOLO, 29., Ribeirão Preto, 2003. Anais. Ribeirão Preto, Sociedade Brasileira de Ciência do Solo, 2003. CD-ROM.

REZENDE, J. O. Solos coesos dos Tabuleiros Costeiros: Limitações agrícolas e manejo. Salvador, SEAGRI-SPA, 2000. 117p. (SEAGRI/SPA, Série Estudos Agrícolas, 1)

RÖMKENS, M.J.M. \& MILLER, R.D. Predicting root size and frequency from one-dimensional consolidation data - A mathematical model. Plant Soil, 35:237-248, 1971.

SILVA, A.R.; LIMA, J.M. \& DIAS JUNIOR, M.S. Efeito da adsorsão de fosfato em parâmetros físicos e na compressibilidade de solos tropicais. R. Bras. Ci. Solo, 23:219-226, 1999.
SILVA, V.R.; REINERT, D.J. \& REICHERT, J.M. Fatores controladores da compressibilidade de um Argissolo Vermelho-Amarelo distrófico arênico e de um Latossolo Vermelho distrófico típico. II - grau de saturação em água. R. Bras. Ci. Solo, 26:9-15, 2002.

TORMENA, C.A.; SILVA, A.P. \& LIBARDI, P.L. Caracterização do intervalo hídrico ótimo de um Latossolo Roxo sob plantio direto. R. Bras. Ci. Solo, 22:573-581, 1998.

TSEGAYE, T. \& HILL, R.L. Intensive tillage effects on spatial variability of soil physical properties. Soil Sci., 163:143154,1998

VASCONCELOS, R.F.B. Comportamento mecânico de um Latossolo Amarelo não saturado sob diferentes sistemas de manejos culturais de cana-de-açúcar. Recife, Universidade Federal Rural de Pernambuco, 2009. 132p. (Tese de Doutorado)

VEPRASKAS, M.J. Cone index of loamy sands as influenced by pore size distribution and effective stress. Soil Sci. Soc. Am. J., 48:1220-1225, 1984.

WU, L.; FENG, G.; LETEY, J.; FERGUSON, L.; MITCHELL, J.; McCULLOUGH-SANDEN, B. \& MARKEGARD, G. Soil management effects on the nonlimiting water range. Geoderma, 114:401-414, 2003.

XU, D. \& MERMOUD, A. Topsoil properties as affected by tillage practices in North China. Soil Tillage Res., 60:11$19,2001$. 